\title{
Yttrium Aluminum Garnet Powder Feedstock for Atmospheric Plasma Spray
}

\author{
Emil Andre Valaker ${ }^{1,2} \cdot$ Fahmi Mubarok $^{2,3} \cdot$ Nuria Espallargas $^{1}$
}

Submitted: 6 June 2019/in revised form: 7 March 2020/Published online: 28 April 2020

(C) The Author(s) 2020

\begin{abstract}
High demands for higher turbine efficiency bring attention to newer and more advanced insulating materials for the high temperature components in the turbine. Yttrium aluminum garnet (YAG) has shown good insulating properties in the previous published research, such as higher temperature limitation and better resistance to calcium-magnesium-alumina-silicate environmental contaminant penetration than the more conventional yttriastabilized zirconia systems. Whereas in literature, coatings of YAG are typically prepared by solution deposition processes, in the present work YAG powder has been prepared for more conventional thermal spraying methods. The goal is to show the potential YAG powders have as a thermal barrier coating. Different approaches for obtaining a successful deposition and a good coating have been explored. Small-sized industrial-supplied powder and larger in-house-made powder have been compared, emphasizing the importance of energy used for deposition and crystallinity in the final coating. Highly crystalline material has successfully been produced with F4 atmospheric plasma spray system without post-treatment or substrate heating.
\end{abstract}

Keywords thermal barrier coatings $\cdot$ YAG $\cdot$ yttrium aluminum garnet

Emil Andre Valaker

emil.a.valaker@ntnu.no

1 Department of Mechanical and Industrial Engineering, Norwegian Tribology Center, Norwegian University of Science and Technology (NTNU), Trondheim, Norway

2 Seram Coatings AS, Trondheim, Norway

3 Department of Mechanical Engineering, Institut Teknologi Sepuluh Nopember, Surabaya, Indonesia

\section{Introduction}

Thermal barrier coatings (TBC) in the form we most commonly know them, or "the current era" as Miller (Ref 1) referred to, have been around since the middle of the 1970s. The well-known system consisting of an yttria-stabilized zirconia (YSZ) insulating top coating and a NiCrAlY metallic bond coat developed by the NASA Lewis Research Centre in Cleveland by Stecura and Leibert $(\operatorname{Ref} 2,3)$ is to the current day one of the most used TBC systems. Despite being the most used, a lot of attention has been given into outperforming the original YSZ since the millennium. Electron-beam physical vapor deposition (EB-PVD) for producing YSZ is known to be a method for producing high-quality columnar structures, often used for the high thermo-mechanically loaded blades of aero engines (Ref 4). The columnar structure is favored in all TBCs due to the structure allowing some deformation in the ceramic layer due to thermal expansion in the substrate. As a result, the thermal stress is limited allowing the ceramic layer to deform rather than causing delamination. Vertical cracking in homogenous ceramic layers is therefore desired when TBCs are produced with atmospheric plasma spraying (APS), which was the original deposition technique used by Stecura and Leibert.

The APS method has high robustness and better economic viability compared to EB-PVD. Therefore, the APS method is normally used for producing TBCs for power generators and static parts in propulsion systems which typically have lower quality demands than the turbine blades in the aero engine (Ref 5,6). At the same time, the need for improvement is high in both areas. Higher inlet temperatures are a factor that highly influences the efficiency and power output of the turbines. The maximum operating temperature of $\mathrm{YSZ}$ is limited to $1200{ }^{\circ} \mathrm{C}$ due to 
the metastable tetragonal phase and reduction of stress tolerances due to sintering; therefore, using YSZ can limit the efficiency and power output of the turbines. Exposure to high temperatures at prolonged periods can cause decomposition into high and low yttria phases, resulting in monoclinic phases upon cooling. Catastrophic events are expected from the associated significant volume increase. In addition, densification of high-crystalline YSZ is expected to start at $1000{ }^{\circ} \mathrm{C}$ and accelerate the decomposition process (Ref 7-11).

As demands for higher turbine efficiency keep increasing, emergence of degradation mechanisms keeps occurring. One of the most discussed and severe issues related to the degradation of TBCs is the exposure to calcium-magnesium-alumina-silicates (CMAS) at elevated temperatures. The CMAS are often introduced to the system from the intake air in the form of dust, sand, volcanic ashes or similar. The most used 7YSZ is proven to be prone to CMAS attacks, and research has been carried out to overcome the potential exposure and degradation (Ref 12-16).

To overcome the limitations of YSZ, a numerous of different materials and systems have been suggested, developed, tested and compared with already accepted solutions. Most of the new developments utilize rare earth metals as stabilizers for the zirconia, mostly with the intention of decreasing conductivity or increasing phase transitions and sintering temperature even further than yttria alone (Ref 1, 17-19). Other materials have been suggested such as, for example, yttrium aluminum garnet (YAG). It is well known and recognized that zirconia and YSZ show insufficient phase stability that can accelerate sintering at as low temperatures as $1200{ }^{\circ} \mathrm{C}$ (Ref 20). However, a material like YAG shows phase stability up to $1970{ }^{\circ} \mathrm{C}$ (close to its melting point), making it an attractive alternative to YSZ in TBC applications because its effective sintering temperature is above $1500{ }^{\circ} \mathrm{C}, 300{ }^{\circ} \mathrm{C}$ higher than YSZ (Ref 21, 22). In addition, work has been carried out on designing new coating systems, often introducing a new layer to the YSZ-metal bond coat system. Alternatively, a state-of-the-art deposition technique called solution precursor plasma spray (SPPS) can produce a feathery and desired micro-columnar structure, which is more similar to the one obtained by EB-PVD methods. This desired SPPS structure is still being researched and optimized (Ref 6, 23-25). The columnar structure obtained with the EB-PVD and SPPS method allows for more cyclic movement and delivers a more flexible system than more conventional APS sprayed TBC from a dry powder feedstock. The columnar structure also presents cracks between the columns, allowing the insulating top layer some horizontal expansion due to cyclic temperature exposure and thermal expansion of the substrate, ultimately hindering catastrophic failure of the system (Ref 26-28). Recently, a lot of published research has also focused on using the SPPS approach with other materials than YSZ, one of them being YAG, a potential contender with what is reported to be promising properties for a future high-performing TBC (Ref 29, 30).

\section{Yttrium Aluminum Garnet}

Yttrium aluminum garnet (YAG) $\left[\mathrm{Y}_{3} \mathrm{Al}_{5} \mathrm{O}_{12}\right]$ is often used in solid-state lasers and is therefore a well-known material (Ref 31-33). In addition, its thermal and mechanical properties make it a very interesting material for a potential TBC, as presented in Table 1. The low density, high hardness and high sintering temperature represent a potential higher quality for most applications where a TBC is crucial. Interestingly, YAG has been proposed as a part of a TBC system before. First by Padture and Klemens (Ref 34) in 1997 from a theoretic perspective purely based on material properties. The first scientific literature showing deposition of YAG by thermal spray methods is presented by Parukuttyamma et al. (Ref 35). At that time, novel precursor plasma spraying (PPS) method was utilized for the deposition, more often referred to as solution precursor plasma spraying (SPPS) in later days by Jordan et al. (Ref 23) and Kumar et al. (Ref 36). Additionally, YAG coatings have been reported to show great resistance to CMAS exposure at elevated temperatures further indicating the potential for the material in TBC systems (Ref 37). YAG coatings have also been produced with more conventional spray methods, as presented by Weyant and Faber (Ref 38).

The promising properties of YAG combined with encouraging published results are to be considered highly relevant for further research. However, more work is needed to better understand the potential of the material and consequences of different deposition techniques. Most published research on YAG as a TBC material emphasized the use in high-risk components and/or extreme exposures. Consequently, most researches on YAG coatings have been carried out with SPPS methods. Therefore, the intention of the present work is to synthesize a dry YAG powder with a large particle size and produce high-crystalline coatings with conventional APS methods. In addition, one industrial-supplied YAG powder has been compared to the inhouse-produced feedstock material. All with the intention of outperforming the more conventional YSZ systems so turbine engines potentially can become more efficient and more durable at higher operating temperatures. 
Table 1 Comparison of material properties of YAG and YSZ

\begin{tabular}{lll}
\hline & \multicolumn{1}{c}{8 YSZ } & \multicolumn{1}{c}{ YAG } \\
\hline Thermal conductivity at $1000{ }^{\circ} \mathrm{C}, \mathrm{W} / \mathrm{m} \mathrm{K}$ & $2.0-3.0($ Ref 39) & $2.3-3.2(\operatorname{Ref} 34)$ \\
Density, $\mathrm{g} / \mathrm{cm}^{3}$ & $5.90-6.13(\operatorname{Ref} 40,41)$ & $4.55($ Ref 42) \\
Thermal expansion, $10^{-6} / \mathrm{K}$ & $7.5-9.5(\operatorname{Ref} 43)$ & $7.7-8.2(\operatorname{Ref} 44)$ \\
Vickers hardness, $\mathrm{HV}$ & $1310(\operatorname{Ref} 45)$ & $1730(\operatorname{Ref} 46,47)$ \\
Melting temperature,${ }^{\circ} \mathrm{C}$ & $2710(\operatorname{Ref} 48)$ & $2048(\operatorname{Ref} 48)$ \\
\hline
\end{tabular}

Table 2 Raw materials used for YAG synthesis

\begin{tabular}{lll}
\hline Raw material & Chemical formula & \multicolumn{1}{c}{ Supplier } \\
\hline Yttrium nitrate hexahydrate & $\mathrm{Y}\left(\mathrm{NO}_{3}\right)_{3} \cdot 6\left(\mathrm{H}_{2} \mathrm{O}\right)$ & Pangea International (China) \\
Aluminum nitrate nonahydrate & $\mathrm{Al}\left(\mathrm{NO}_{3}\right)_{3} \cdot 9\left(\mathrm{H}_{2} \mathrm{O}\right)$ & Honeywell (EU) \\
Urea & $\mathrm{CO}\left(\mathrm{NH}_{2}\right)_{2}$ & EcoUrea (Norway) \\
\hline
\end{tabular}

\section{Experimental Procedure}

\section{Material Synthesis}

Production of YAG can be carried out in many forms. This paper focuses on dry powder synthesis through the coprecipitation method (Ref 49-51). The two metal ions (aluminum and yttrium) were delivered in the form of nitrites, and urea was used to control the $\mathrm{pH}$ of the system.

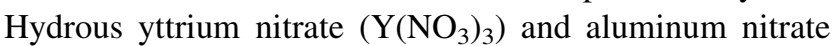
$\left(\mathrm{Al}\left(\mathrm{NO}_{3}\right)_{3}\right)$ were dissolved and mixed in water in a stoichiometric metal atomic ratio of 3:5, respectively $\left(\mathrm{Y}^{3+} /\right.$ $\mathrm{Al}^{3+}$ ); see Table 2 for raw material information. This is known as the salt precursor, which was then added in the form of droplets into a high-molarity urea solution during constant stirring and constant heating $\left(T=90{ }^{\circ} \mathrm{C}\right)$.

The precipitates generated at the end of the titration process (yttrium and aluminum salts) were filtered with a mechanical filter press to remove the excess of water and other chemicals. Following, the filtered product was dried at $200{ }^{\circ} \mathrm{C}$ for $24 \mathrm{~h}$.

After drying, the material was heat-treated to slowly burn off the non-reacted chemicals and transform the yttrium and aluminum salt precursors into crystalline YAG. For this purpose, the material was heat-treated in air atmosphere at $1150{ }^{\circ} \mathrm{C}$ for $4 \mathrm{~h}$. The intention of the temperature chosen was to form a fully crystalline material with small crystal grain size. Even though crystallization for YAG is known to start around $900{ }^{\circ} \mathrm{C}$ (Ref 52, 53), higher temperature is needed to fully crystallize all the material.

\section{Powder Preparation}

After heat treatment, ball milling was used to obtain a suitable powder size for thermal spraying. The material altered several times between ball milling and vibratory sieving, continuously extracting desired powder sizes. Stacked mesh sizes and multiple runs were carried out. Mesh sizes used were 40-80, 50-100 and 100-150 $\mu \mathrm{m}$. A simplified schematic process of producing dry YAG powder is presented in Fig. 1.

Particle size distribution (PSD) was obtained for the different powders with ultrasonic mixing submerged in deionized water. The procedure was carried out according to ISO 13320:2009 (Ref 54) (Malvern Panalytical, Mastersizer 3000E, UK).

\section{Atmospheric Plasma Spraying (APS)}

As mentioned, many different thermal deposition methods can be used for producing TBCs (i.e., high-melting temperature oxides). APS being the most used due to the high energy output and high temperature needed enabling splats to form upon impact. The spraying parameters for producing TBCs of YAG logically should vary from standard parameters typically used for YSZ coatings due to their different physical and chemical properties. The lower melting point of YAG, closer to alumina and titania (Table 1), indicates that lower energy is needed to form a suitable structure and integrity. The tailored spraying program required a modification of the existing spraying parameters used for more familiar materials, such as YSZ, titania and alumina. Spraying parameters typically used and reported by other researchers for these materials were adopted and adjusted to better suit the large YAG powder size and its different chemical properties. Spraying parameters were optimized with the intention of finding an optimum coating microstructure. The most optimal spraying parameters with respect to microstructural characterization are presented in Table 3. 


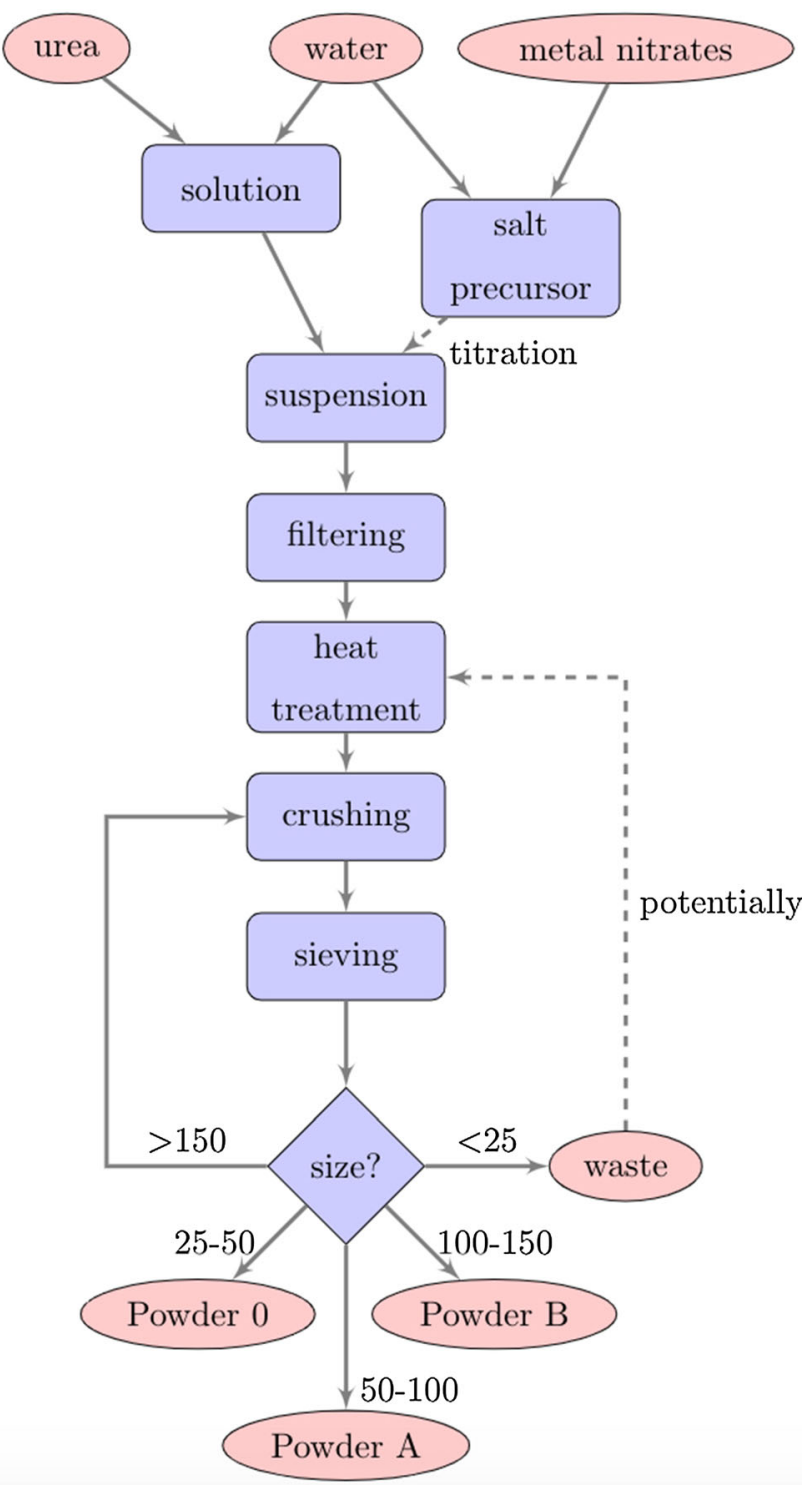

Fig. 1 Simplified flowchart for in-house YAG powder production route

In addition, industrial-supplied YAG powder was sprayed together with the in-house-made powders. This is a smaller-sized powder stated to rather produce dense highintegrity TBCs. Parameters for spraying the industrialsupplied powder with the F4 spraying system were given by the powder supplier together with the powder material.

\section{Coating Characterization}

Post-spraying, the 5-mm-thick mild steel substrate and the coatings were cut into 6-mm-wide slices. Due to the potential damaging effect of thermally sprayed coatings with violent sectioning, a precision cutting machine was used to minimize the influence of the coating (Struers, Accutom-50, Denmark with an $\mathrm{Al}_{2} \mathrm{O}_{3}$ cutting wheel).
The brittle and porous coating needed additional support for further preparation. The slices were therefore embedded with vacuum impregnation using a slow-curing, high-retention epoxy resin (Struers, EpoFix, Denmark). The epoxy resin was intended to fill up open porosity to enhance the best integrity possible for further handling. Forty-millimeter holders were used for the embedding.

When the sample embedding material had fully cured for $24 \mathrm{~h}$, the samples were ground and polished to produce a representative cross section of the coating. TBCs are known for their difficult preparation (Ref 55, 56). The method used in this work is described in Table 4.

Coating hardness measurement was taken with microhardness indentation on polished cross section according to ASTM C1327-15 (Ref 57) (Mitutoyo USA, HM-210 Type A $V / K)$.

$\mathrm{X}$-ray diffraction (XRD) was carried out on both powder feedstock material and coatings (Bruker D8 A25 DaVinci x-ray Diffractometer with $\mathrm{Cu} K \alpha$ radiation, Germany).

The images of the powder were obtained with scanning electron microscopy (SEM) on carbon tape (Thermo Fisher-FEI Quanta 650 FEG ESEM, US), and images of cross section of the coating were obtained with optical microscopy (Olympus BX53M, Japan). Three independent images for each coating were further analyzed with image software (ImageJ.net) to estimate internal porosity. Based on the $2 \mathrm{D}$ cross section, a rectangular area was chosen as a function of coating thickness and a width of $1200 \mu \mathrm{m}$.

\section{Results and Discussion}

\section{Thermal Spray Feedstock}

The synthesis route chosen for this work resulted in porous dried rocks of YAG before crushing. These porous rocks were crushed down and separated. Final powder morphology can be seen in Fig. 2 (note that the images are taken at different magnifications for the sake of clarity). The irregular shapes allowed larger particle than the actual mesh size chosen to pass and therefore shifted the PSD toward larger sizes, both for upper and lower meshes. The PSD is presented in Table 5.

Cross section characterization of the powders showed that porosity was present in the powder particle. Embedded and polished powder particles from Powder B are presented in Fig. 3. Crushed particles are normally referred to as sintered and crushed, corresponding to their dense appearance and blocky shapes. In this work, the heat treatment performed was a calcination process at temperatures just above crystallization temperature for YAG (i.e., $\left.900{ }^{\circ} \mathrm{C}\right)$. YAG has been reported to initiate densification at around $1100{ }^{\circ} \mathrm{C}$; however, densification rates are 
Table 3 Spraying parameters used for deposition with F4 spraying system

\begin{tabular}{llllll}
\hline Coating ref. & \multicolumn{1}{c}{ Industrial coating $^{\mathrm{a}}$} & Coating 1 & Coating 2 & Coating 3 & Coating 0 \\
\hline Powder ref. & Industrial YAG powder & Powder A & Powder B & Powder 0 \\
Powder size, $\mu \mathrm{m}$ & $+15 /-44$ & \multicolumn{2}{c}{$+55 /-138$} & $+101 /-182$ & $+18 /-63$ \\
Ar, slpm & 40 & 40 & 35 & 40 & 40 \\
$\mathrm{H}_{2}$, slpm & 14 & 12 & 6 & 12 & 12 \\
Current, A & 600 & 600 & 540 & 600 & 600 \\
Potential, $\mathrm{V}$ & 68 & 63 & 50 & 63 & 64 \\
Power, $\mathrm{kW}$ & 41 & 38 & 27 & 38 & 38 \\
Spray distance, mm & 120 & 120 & 150 & 150 & 120 \\
Feed rate, g/min & 10.0 & 9.5 & 9.5 & 9.5 & 10.0 \\
Gun speed, mm/s & 400 & 200 & 200 & 200 & 200 \\
Thickness/pass, $\mu \mathrm{m}$ & 35 & 70 & 55 & 50 & 37 \\
Passes, - & 25 & 10 & 15 & 18 & 7 \\
Thickness, $\mu \mathrm{m}$ & 880 & 700 & 820 & 910 & 260 \\
\hline
\end{tabular}

${ }^{\text {a }}$ The parameters used for spraying the industrial-supplied powder were delivered by the powder manufacturer
Table 4 Grinding and polishing procedure

\begin{tabular}{|c|c|c|c|c|c|}
\hline Step & Surface & Abrasive & Lubricant & Force, $\mathrm{N}$ & Time, min \\
\hline 1 & Diamond pad 220 & $\ldots$ & Water & 40 & 2 \\
\hline 2 & $\mathrm{SiC}$ paper 800 & $\ldots$ & Water & 50 & 1 \\
\hline 3 & Hard composite pad & $9-\mu \mathrm{m}$ diamond & Ethanol based & 30 & 9 \\
\hline 4 & Woven acetate pad & $3-\mu \mathrm{m}$ diamond & Ethanol based & 30 & 3 \\
\hline 5 & Woven silk pad & $1-\mu \mathrm{m}$ diamond & Ethanol based & 20 & 1 \\
\hline
\end{tabular}

significantly higher above $1500{ }^{\circ} \mathrm{C}(\operatorname{Ref} 21,58,59)$. The goal of this work was to obtain a crystalline structure of the YAG with small crystal sizes and high amount of grain boundaries. Therefore, a calcination route at $1150{ }^{\circ} \mathrm{C}$ was chosen, and the powder contains porosity.

One of the main aspects with the chosen powder synthesis route was the freedom of controlling the resulting crystallinity of the powder. The route selected for the current work allowed tailoring of the crystal size and amount of grain boundaries during the last step of the heat treatment. The intention of the high amount of grain boundaries is firstly to increase the integrity of the YAG powder upon impact during thermal spraying promoting more porosity in the deposited layer, and secondly, to hinder amorphization of the material during coating deposition. Preliminary studies and other published research by Weyant and Faber (Ref 38) have shown that YAG easily forms amorphous coating by thermal spraying. Therefore, higher amount of grain boundaries is expected to obstruct the amorphization during the thermal spray process.

The crystallinity of the powders was studied using X-ray diffraction (XRD). For comparison purposes, powders A/B were also sintered at $1750{ }^{\circ} \mathrm{C}$. In Fig. 4, XRD spectra of the different powder materials are presented. From the magnified area, it is clear that the crystal size in the original in-house YAG powder was smaller compared to the same powder sintered at a higher temperature and the powder delivered by the industrial supplier. The shape of the peaks (broader for the in-house powder) clearly indicated that the powder with the lower-temperature heat treatment has a smaller crystal size than the powders sintered at higher temperature. Post-processing and dedicated spectra analyzing software were used to try to quantify the actual crystal size using the Scherrer equation with non-trustworthy results, and the results were therefore discarded and are not presented in this paper. However, peak broadening in XRD is already a good and clear indication of differences in crystallinity for materials.

\section{Coating Crystallinity}

Coatings sprayed with APS F4 system using the spraying parameters shown in Table 3 were analyzed by XRD to study the effect of powder heat treatment and PSD on crystallinity of the final coating. XRD spectra of the coatings are presented in Fig. 5. It is clear that the smallsized industrial powder did not retain the crystalline structure and full amorphization is observed. However, this is also observed for Coating 0 made from calcined small- 


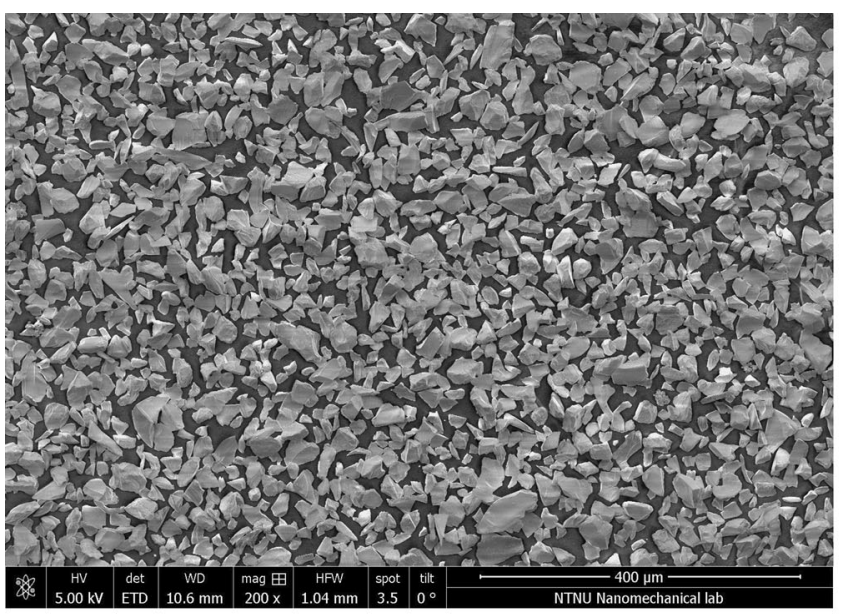

(a)

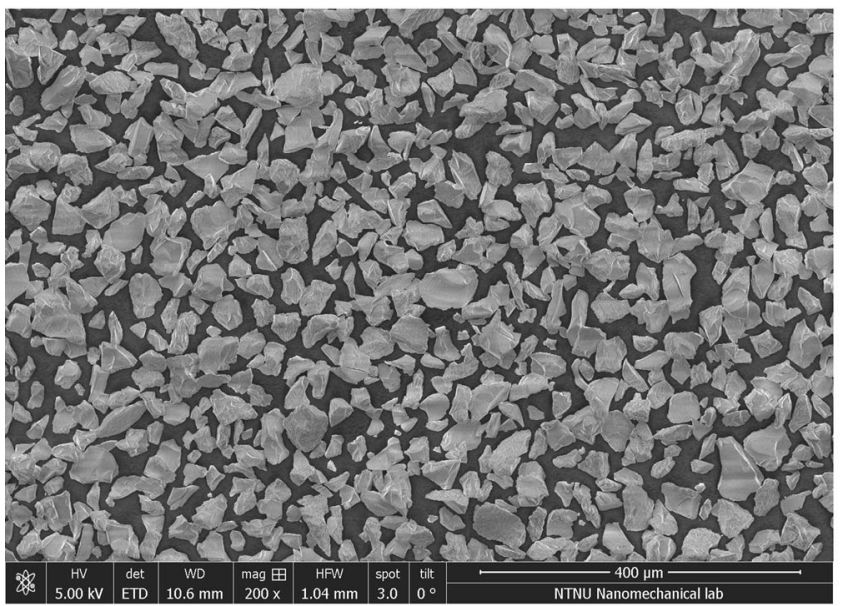

(b)

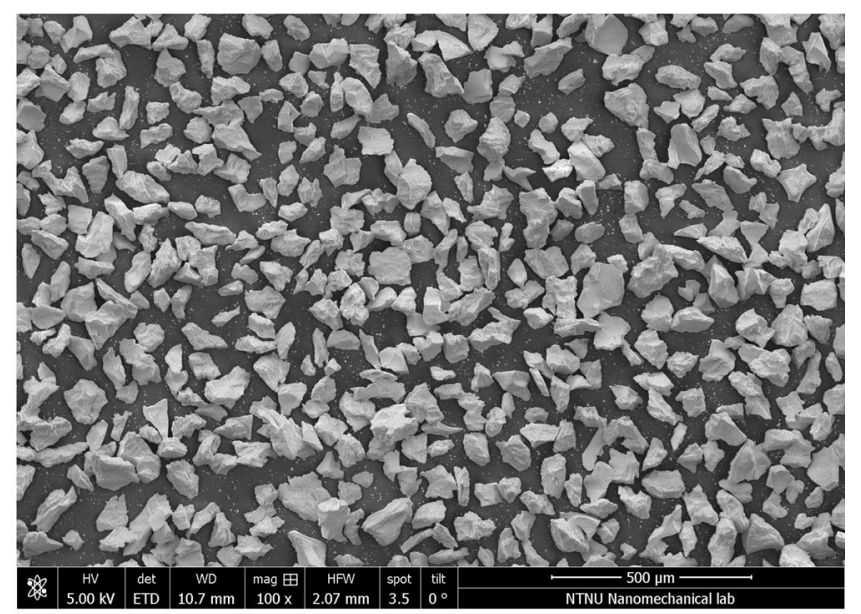

(c)

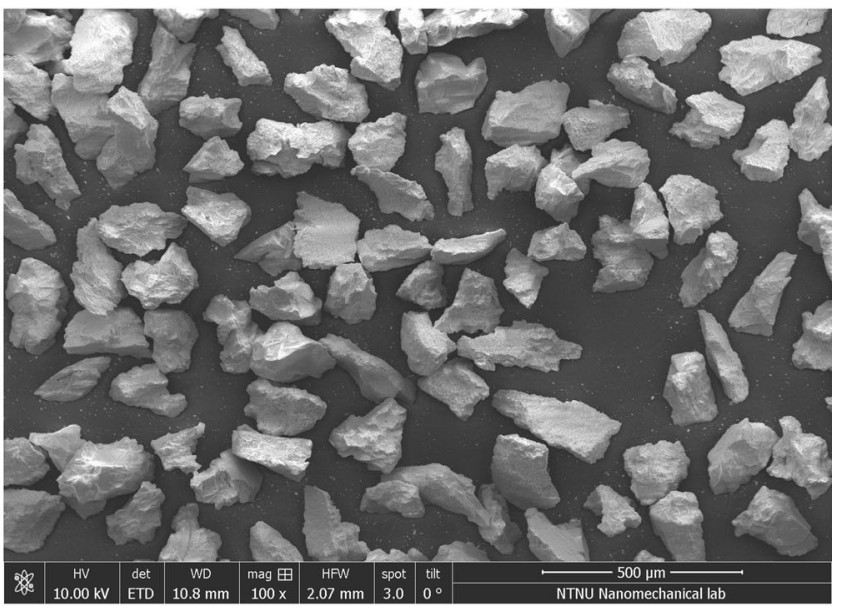

(d)

Fig. 2 SEM images of the three different powders used for producing TBC of YAG

Table 5 Particle size analysis of separated powder particles in $\mu \mathrm{m}$

\begin{tabular}{lccrrr}
\hline Powder ref. & Lower mesh & Upper mesh & D10 & D50 & D90 \\
\hline Industrial YAG & $\ldots$ & $\ldots$ & 15 & 26 & 44 \\
Powder 0 & 25 & 50 & 18 & 31 & 63 \\
Powder A & 50 & 100 & 55 & 88 & 138 \\
Powder B & 100 & 150 & 101 & 141 & 182 \\
\hline
\end{tabular}

size powder. Again, as the previous research indicates, producing a well-functioning TBC system is dependent on fully crystalline structure being preserved from the powder state. There is the literature producing fully crystalline YAG coatings from powder by Ref 38 . This was carried out via heating the substrate resulting in slower cooling rates of the deposited material. This could be considered to be a controversial method due to requirements often stating that substrate temperature should be kept at a minimum and

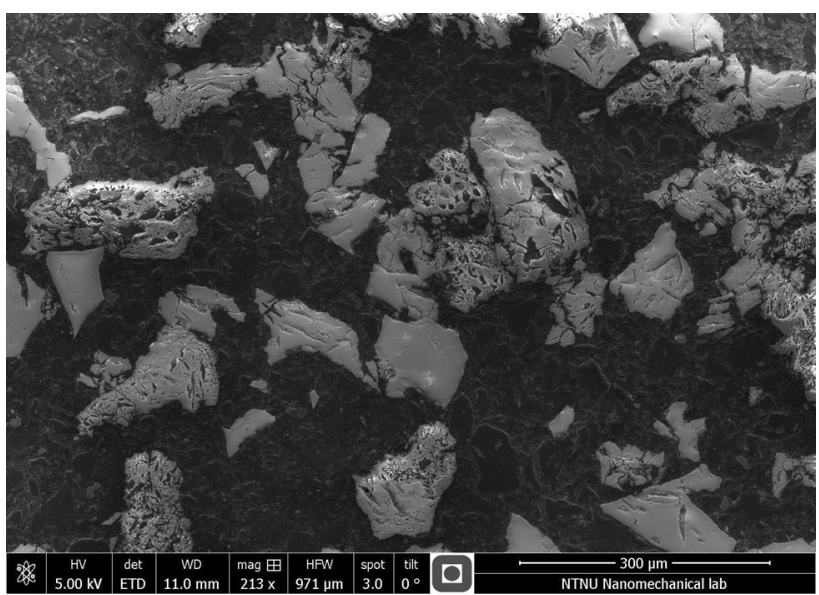

Fig. 3 Cross section of Powder B obtained in SEM

lower than given temperatures (Ref 60). On the contrary, this paper demonstrates that crystallinity can be achieved with a more subtle approach in terms of thermal spraying 
Fig. 4 XRD spectra of three different YAG powders

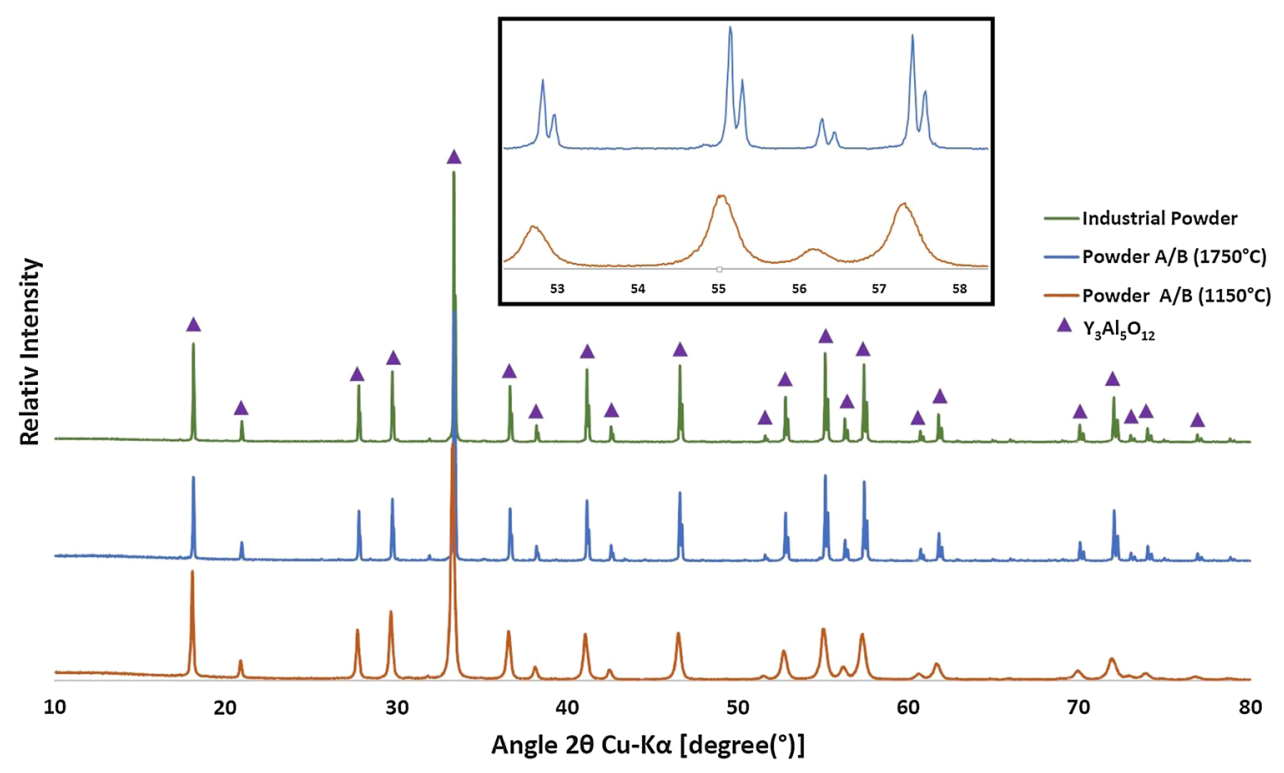

Fig. 5 XRD spectra of the YAG coatings and YAG powder $\mathrm{A} / \mathrm{B} / 0$ for comparison

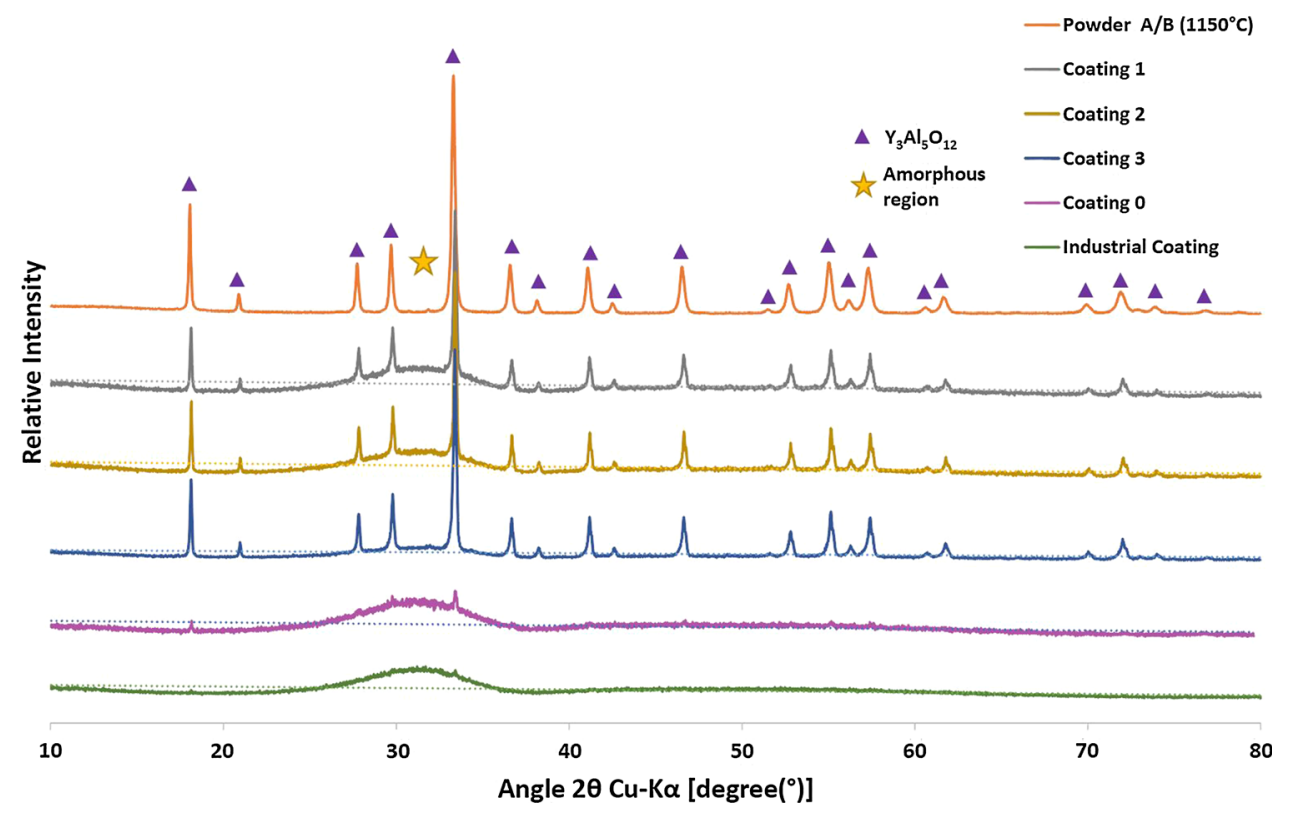

energy which should be considered for application where substrate temperature needs to be kept at a minimum during spraying.

From the XRD spectra in Fig. 5, it is observed that crystallinity in the coating is very much dependent on the powder particle size, rather than the spraying parameters and powder crystallinity from heat treatment. Coating 0 was sprayed with same parameters as Coating 1 , the powder size being the only difference between them. In this case, the smallest powder (Coating 0) did not retain the crystalline structure, whereas the largest powder did.

Interestingly, the industrial coating produced from powder of similar particle size as Coating 0 , but higher crystallinity, did not retain the crystallinity either. The coating that retained most of the crystallinity was Coating 3 , which was produced from the largest powder size and heat-treated at lower temperatures (i.e., $1150{ }^{\circ} \mathrm{C}$ ). The results strongly indicate that particle size is more important than initial crystal size for retaining the crystallinity in the coatings.

\section{Coating Morphology}

Cross sections of four coatings are presented in Fig. 6. These images clearly show differences in microstructure obtained as a function of particle size and deposition energy. The differences in microstructure observed were more significant for the coating produced from the small- 


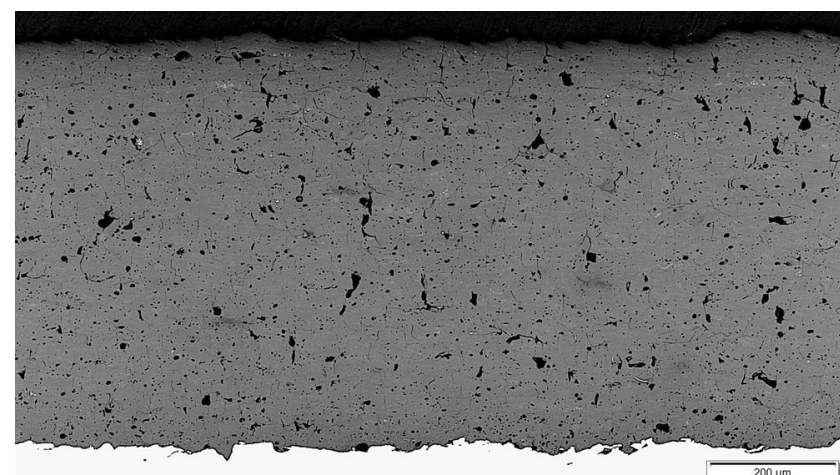

(a)

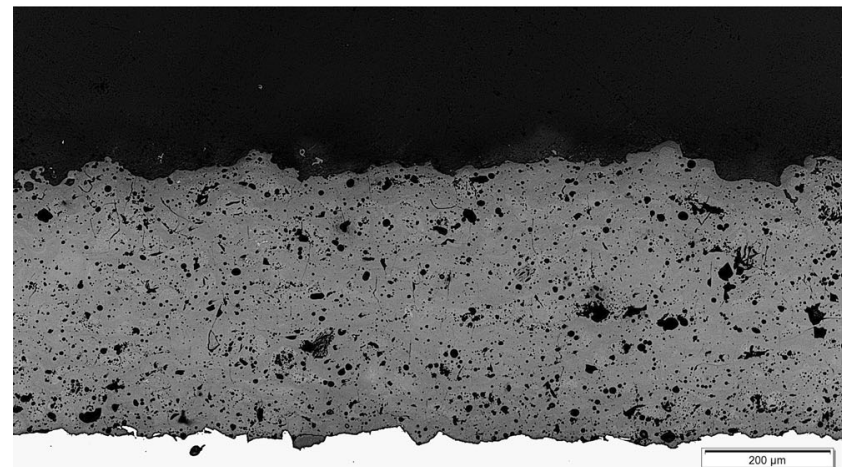

(b)

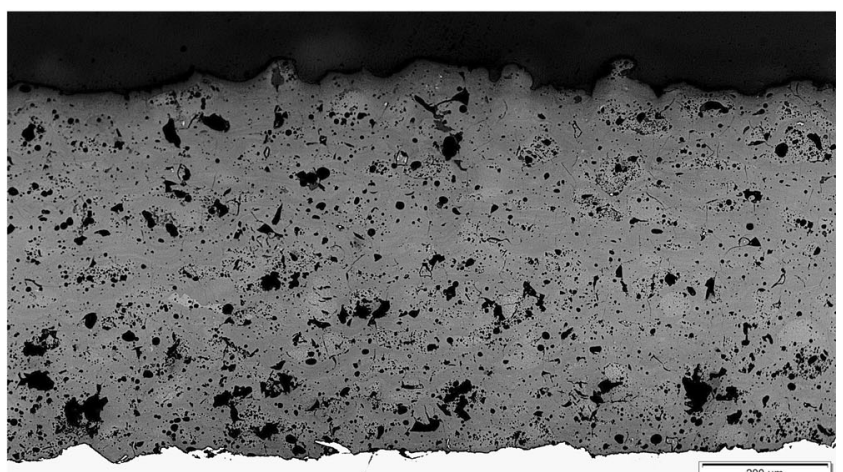

(c)

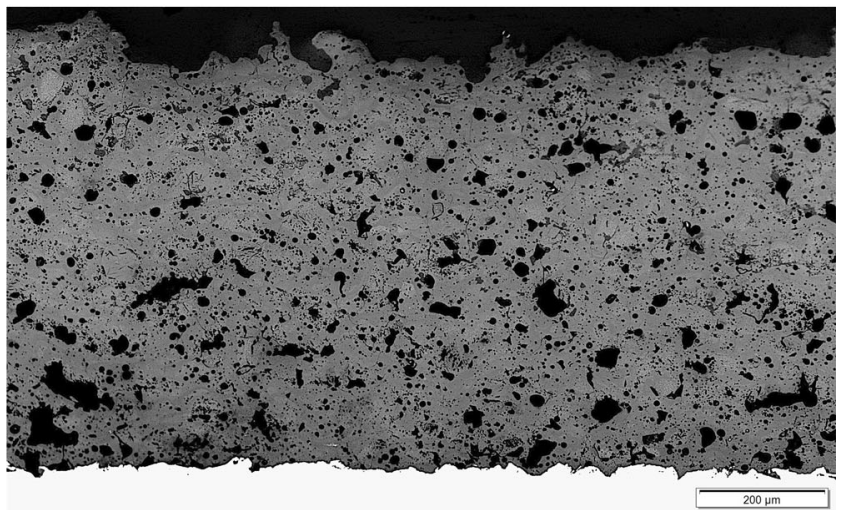

(d)

Fig. 6 Images obtained from the cross section of the vacuum-embedded epoxy samples

sized industrial-supplied YAG powder, which can be observed in Fig. 6(a). All coatings made from this powder had a denser and more uniform structure with evidently lower porosity. Despite being denser, this was the coating where the most amount of small vertical cracks was observed. This can be an indication of the presence of more internal stresses in the coating. Some vertical cracks could also be observed in the other coatings as seen in Fig. 7. However, the coatings obtained with the in-house-made powder were more dominated by larger, homogenous, spherical pores compared to the industrial coating. Homogenous pores combined with low internal stress are desired to facilitate the thermal expansion mismatch with substrates to ensure high durability.

\section{Porosity}

Internal porosity for the individual coatings is presented in Table 6. Due to the difficulty of preparing TBCs without introducing manipulations in the cross sections, such as pullouts, porosity can potentially be misinterpreted. Therefore, porosity should be estimated carefully for distinguishing between real porosity and introduced pores. The presence of pores larger than the D90 powder particle size is generally considered as pullouts in pore analysis and should therefore neglected for porosity calculations. However, it is worth noticing that all pores observed in our coatings were smaller than what corresponded to the area of a D90 particle, leading to grounds for assuming that pullouts were not created during sample preparation in this work.

It is clear that the porosity in the coating is strongly related to the particle size used for depositing the material. Even though differences in spraying energy used for deposition changed the porosity (Coating 1 versus Coating 2 ), more energetic spraying parameters (Coating 1) did not bring significant differences in porosity with respect to Coating 2. Note that these two coatings were sprayed with same PSD. In addition, it was observed that the average pore size was larger for Coating 2 than for Coating 1, which is expected due to lower spraying energy used. However, it can also be observed that Coating 2 had a larger average pore size than Coating 3 despite being produced from smaller particles. This is another indication that the large-sized Powder B did not experience enough heat throughout the particle during deposition. The high amount of small-sized porosity (less than $1 \mu^{2}$ ) observed is believed to have come from that originally contained in 


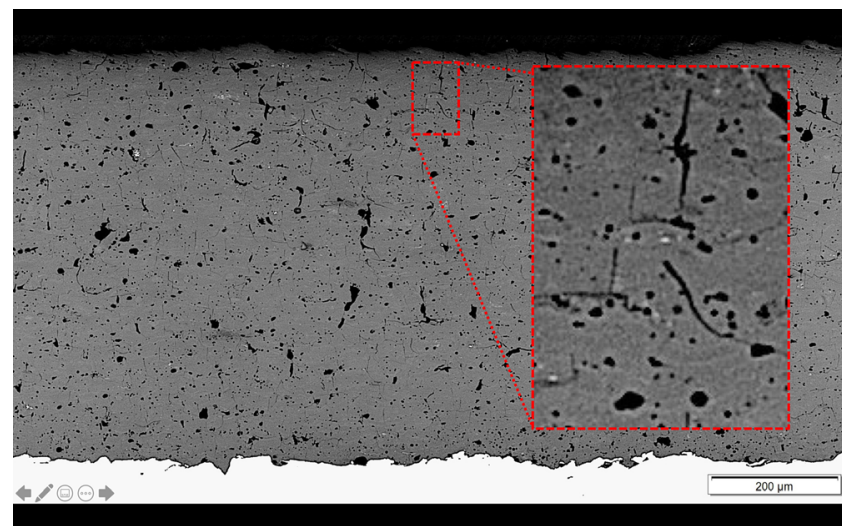

(a)

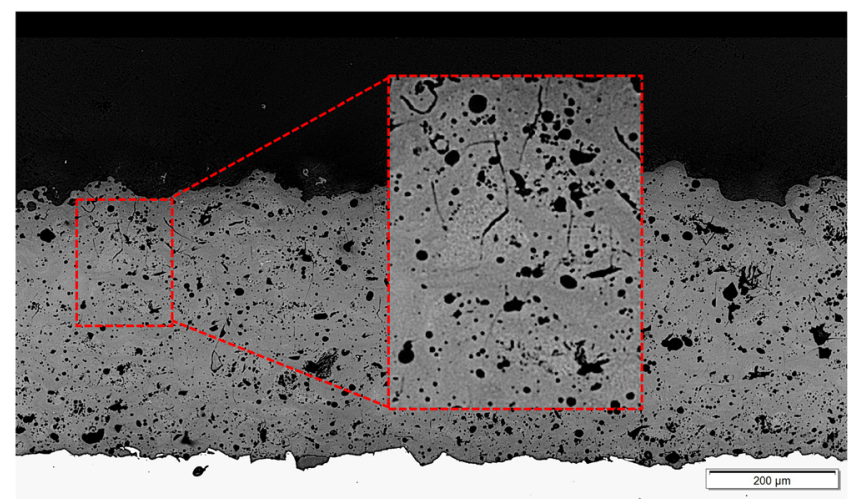

(b)

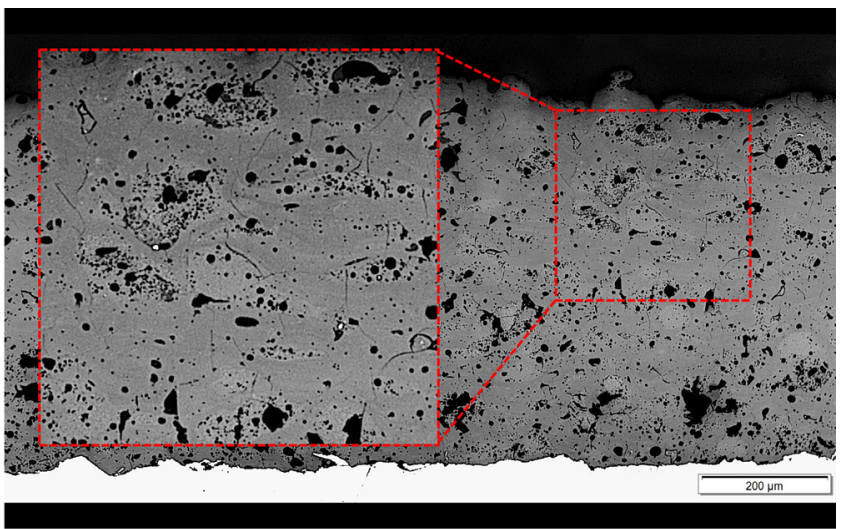

(c)

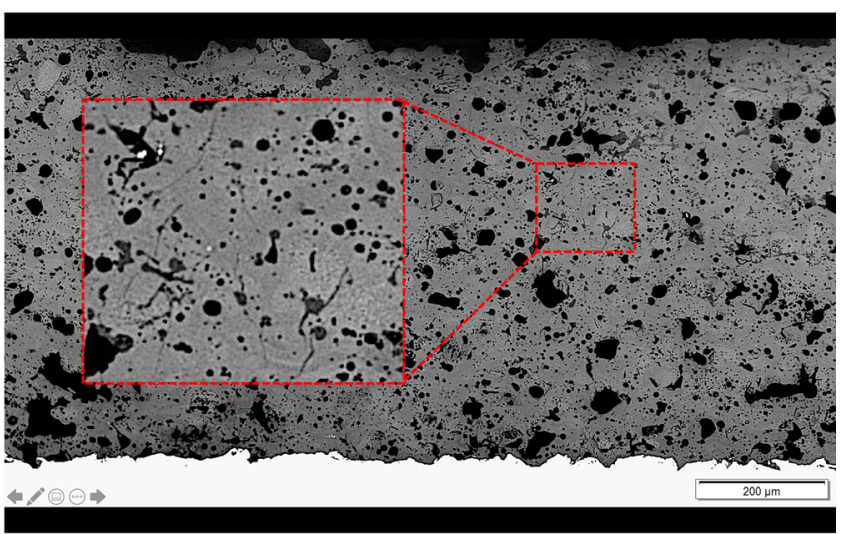

(d)

Fig. 7 Highlighted pores and cracks from the cross section

Table 6 Porosity in coatings obtained from 2D image analysis

\begin{tabular}{lccc}
\hline Coating ref. & Porosity, $\%$ & Standard deviation, $\%$ & Average pore area $\left(A=\mu \mathrm{m}^{2}\right)$ \\
\hline Industrial coating & 4.18 & 0.12 & 7.92 \\
Coating 1 & 11.09 & 0.42 & 26.7 \\
Coating 2 & 12.89 & 1.67 & 49.4 \\
Coating 3 & 16.90 & 1.98 & 38.3 \\
\hline
\end{tabular}

Table 7 Hardness values obtained for the coatings (cross section) according to ASTM C1327-15

\begin{tabular}{lcccc}
\hline Coating ref. & Mean hardness & SD & Valid indents & Valid (\%) indents \\
\hline Industrial coating & $789 \mathrm{HV} 0.3$ & 50.8 & 8 & 73 \\
Coating 1 & $746 \mathrm{HV} 0.3$ & 30.3 & 8 & 35 \\
Coating 2 & $725 \mathrm{HV} 0.3$ & 41.2 & 8 & 33 \\
Coating 3 & $823 \mathrm{HV} 0.3$ & 87.6 & 8 & 20 \\
\hline
\end{tabular}

the powder particles (Fig. 3) and not to have formed as part of the coating process.

\section{Hardness}

Microhardness values are presented in Table 7. It is clear that all hardness values are highly influenced by the porosity, i.e., the higher the porosity of the powder, the less the valid indents in the microhardness measurements. This is to be expected in brittle ceramic materials like YAG. The difference in hardness between the coatings is small, but noticeable. The highest hardness observed in Coating 3 is believed to be a result of the higher crystallinity retained in the coating compared to the others (Fig. 5). However, the 
porosity strongly influences how the material responds to the load of the microindenter. Eighty percent of the indents conducted in Coating 3 had to be classified as invalid according to the procedure of ASTM C1327-15 (Ref 57). Fewer discarded indents were observed in the other coatings, but still more than $50 \%$ of the indents were invalid for the coatings produced with the in-house-made powders. The ratio of indents resulting in valid indents is here observed to be of greater importance than hardness values alone. Meaning, the hardness number alone is not a clear indication of integrity in TBCs.

\section{Conclusions}

Based on the results obtained in this work, some concluding remarks were made and should be considered for further research.

- This work proves that a top coating of YAG with morphological characteristics to perform in a TBC system (i.e., uniform porosity and minor vertical crack formation) can be produced using YAG powder. However, special care is to be taken in controlling the heat treatment of the powder and the powder size to obtain an optimal coating microstructure.

- Crystalline YAG coatings can be produced by APS from a powder feedstock, but $100 \%$ crystallinity was not observed in any of the coatings. However, using a less energetic spraying system (e.g., 3 MB type) and further optimization of powder morphology, it would be possible to achieve higher degrees of crystallinity.

- For obtaining a higher degree of crystallinity in the YAG coatings, the powder particle size is the most important parameter in the powder feedstock material, more than crystal grain size.

- This work has shown an alternative approach to obtain high crystallinity oxide coatings. For achieving a favorable microstructure in the coating, no post-heat treatment or in situ heating of the substrate was needed. Instead, following a powder feedstock heat treatment and powder size distribution strategy successfully achieved the goal of coating crystallinity.

\footnotetext{
Acknowledgments Open Access funding provided by NTNU Norwegian University of Science and Technology (incl St. Olavs Hospital - Trondheim University Hospital). The authors would like to thank Dag Abrahamsen in Struers Norge A/S for contributing in developing a suited sample preparation path for these new highly porous oxide coatings. The authors are grateful for the financial support from The Research Council of Norway for funding the industrial Ph.D. Project 263879/O30.
}

Open Access This article is licensed under a Creative Commons Attribution 4.0 International License, which permits use, sharing, adaptation, distribution and reproduction in any medium or format, as long as you give appropriate credit to the original author(s) and the source, provide a link to the Creative Commons licence, and indicate if changes were made. The images or other third party material in this article are included in the article's Creative Commons licence, unless indicated otherwise in a credit line to the material. If material is not included in the article's Creative Commons licence and your intended use is not permitted by statutory regulation or exceeds the permitted use, you will need to obtain permission directly from the copyright holder. To view a copy of this licence, visit http://creativecommons. org/licenses/by/4.0/.

\section{References}

1. R.A. Miller, Thermal Barrier Coatings for Aircraft Engines: History and Directions, J. Therm. Spray Technol., 1997, 6(1), p $35-42$

2. S. Stecura, Two-Layer Thermal Barrier Coating for Turbine Airfoils-Furnace and Burner Rig Test Results. Technical report (NASA Lewis Research Center, Cleveland, 1976)

3. S. Stecura, C.H. Leibert, Thermal Barrier Coating System. Technical report (NASA Lewis Research Center, Cleveland, 1977)

4. R. Vassen, M.O. Jarligo, T. Steinke, D.E. Mack, and D. Stöver, Overview on Advanced Thermal Barrier Coatings, Surf. Coat. Technol., 2010, 205(4), p 938-942

5. A.G. Evans, D.R. Mumm, J.W. Hutchinson, G.H. Meier, and F.S. Pettit, Mechanisms Controlling the Durability of Thermal Barrier Coatings, Prog. Mater Sci., 2001, 46(5), p 505-553

6. D.R. Clarke, M. Oechsner, and N.P. Padture, Thermal-Barrier Coatings for More Efficient Gas-Turbine Engines, MRS Bull., 2012, 37(10), p 891-898

7. F. Rueda artnez, A. Rueda Martnez, M. Toledo Velazquez, P. Quinto Diez, G. Tolentino Eslava, and J. Abugaber Francis, Évaluation of the Gas Turbine Inlet Temperature with Relation to the Excess Air, Energy Power Eng., 2011, 03(04), p 517-524

8. G. Witz, V. Shklover, W. Steurer, S. Bachegowda, and H.P. Bossmann, Phase Evolution in Yttria-Stabilized Zirconia Thermal Barrier Coatings Studied by Rietveld Refinement of X-Ray Powder Diffraction Patterns, J. Am. Ceram. Soc., 2007, 90(9), p 2935-2940

9. R.L. Jones and D. Mess, Improved Tetragonal Phase Stability at 1400c with Scandia, Yttria-Stabilized Zirconia, Surf. Coat. Technol., 1996, 86-87, p 94-101

10. M. Han, X. Tang, and W. Shao, The Properties of YSZ Electrolyte Sintering at 1300 c, J. Wuhan Univ. Technol.-Mater. Sci. Ed., 2008, 23(6), p 775-778

11. A. Cipitria, I.O. Golosnoy, and T.W. Clyne, A Sintering Model for Plasma-Sprayed Zirconia TBCs. Part I: Free-Standing Coatings, Acta Mater., 2009, 57(4), p 980-992

12. F.H. Stott, D.J. de Wet, and R. Taylor, The Effects of Molten Silicate Deposits on the Stability of Thermal Barrier Coatings for Turbine Applications at Very High Temperatures. In 24th International SAMPE Technical Conference, vol. 24 (1992), p 92-101.

13. D.J. de Wet, R. Taylor, and F.H. Stott, Corrosion Mechanisms of $\mathrm{ZrO}_{2}-\mathrm{Y}_{2} \mathrm{O}_{3}$ Thermal Barrier Coatings in the Presence of Molten Middle-East Sand, Le J. Phys. IV, 1993, 03(C9), p C9-655-C9663

14. J. Kim, M.G. Dunn, A.J. Baran, D.P. Wade, and E.L. Tremba, Deposition of Volcanic Materials in the Hot Sections of Two Gas Turbine Engines, J. Eng. Gas Turbines Power, 1993, 115(3), p 641

15. G. Pujol, F. Ansart, J.-P. Bonino, A. Malié, and S. Hamadi, Stepby-Step Investigation of Degradation Mechanisms Induced by 
CMAS Attack on YSZ Materials for TBC Applications, Surf. Coat. Technol., 2013, 237, p 71-78

16. S. Krämer, J. Yang, C.G. Levi, and C.A. Johnson, Thermochemical Interaction of Thermal Barrier Coatings with Molten CaO-MgO- $\mathrm{Al}_{2} \mathrm{O}_{3}-\mathrm{SiO}_{2}$ (CMAS) Deposits, J. Am. Ceram. Soc., 2006, 89(10), p 3167-3175

17. J. Karthikeyan, C.C. Berndt, J. Tikkanen, S. Reddy, and H. Herman, Plasma spray Synthesis of Nanomaterial Powders and Deposits, Mater. Sci. Eng. A, 1997, 238(2), p 275-286

18. J.M. Drexler, C.-H. Chen, A.D. Gledhill, K. Shinoda, S. Sampath, and N.P. Padture, Plasma Sprayed Gadolinium Zirconate Thermal Barrier Coatings that are Resistant to Damage by Molten Camgalsilicate Glass, Surf. Coat. Technol., 2012, 206(19-20), p 3911-3916

19. M.P. Schmitt, A.K. Rai, R. Bhattacharya, D. Zhu, and D.E. Wolfe, Multilayer Thermal Barrier Coating (TBC) Architectures Utilizing Rare Earth Doped YSZ and Rare Earth Pyrochlores, Surf. Coat. Technol., 2014, 251, p 56-63

20. K. Dychton, M. Drajewicz, M. Pytel, P. Rokicki, and A. Nowotnik, Yttria-Stabilized Zirconia Alumina Composite Sintering Temperature effect on Thermal Diffusivity, J. Therm. Anal. Calorim., 2016, 126(1), p 1-7

21. Y. Huang, D. Jiang, J. Zhang, Z. Chen, Q. Lin, and Z. Huang, Sintering Kinetics of YAG Ceramics, J. Rare Earths, 2014, 32(5), p 416-422

22. M. Gell, J. Wang, R. Kumar, J. Roth, C. Jiang, and E.H. Jordan, Higher Temperature Thermal Barrier Coatings with the Combined Use of Yttrium Aluminum Garnet and the Solution Precursor Plasma Spray Process, J. Therm. Spray Technol., 2018, 27(4), p 543-555

23. E.H. Jordan, L. Xie, M. Gell, N.P. Padture, B. Cetegen, A. Ozturk, X. Ma, J. Roth, T.D. Xiao, and P.E.C. Bryant, Superior Thermal Barrier Coatings Using Solution Precursor Plasma Spray, J. Therm. Spray Technol., 2004, 13(1), p 57-65

24. S. Govindarajan, R.O. Dusane, and S.V. Joshi, Understanding the formation of vertical cracks in solution precursor plasma sprayed yttria-stabilized zirconia coatings, J. Am. Ceram. Soc., 2014, 97(11), p 3396-3406

25. B. Bernard, A. Quet, L. Bianchi, A. Joulia, A. Malié, V. Schick, and B. Rémy, Thermal Insulation Properties of YSZ Coatings: Suspension Plasma Spraying (SPS) Versus Electron Beam Physical Vapor Deposition (EB-PVD) and Atmospheric Plasma Spraying (APS), Surf. Coat. Technol., 2017, 318, p 122-128

26. M.J. Maloney. Patent US6284323B1-Thermal Barrier Coating Systems and Materials, 1996

27. N. Curry, K. VanEvery, T. Snyder, and N. Markocsan, Thermal conductivity analysis and lifetime testing of suspension plasmasprayed thermal barrier coatings, Coatings, 2014, 4(3), p 630-650

28. N.P. Padture, Advanced structural ceramics in aerospace propulsion, Nat. Mater., 2016, 15(8), p 804-809

29. D. Chen, E.H. Jordan, M.W. Renfro, and M. Gell, Dy:Yag Phosphor Coating Using the Solution Precursor Plasma Spray Process, J. Am. Ceram. Soc., 2009, 92(1), p 268-271

30. E.H. Jordan, M. Gell, R. Kumar, and C. Jiang, Yttrium Aluminum Garnet Based Thermal Barrier Coatings, US Patent 2016/0257618, 2016

31. J. Lu, K. Ueda, H. Yagi, T. Yanagitani, Y. Akiyama, and A.A. Kaminskii, Neodymium Doped Yttrium Aluminum Garnet $\left(\mathrm{Y}_{3} \mathrm{Al}_{5} \mathrm{O}_{12}\right)$ Nanocrystalline Ceramics a New Generation of Solid State Laser and Optical Materials, J. Alloys Compd., 2002, 341(12), p 220-225

32. H. Abramczyk, Lasers. In Introduction to Laser Spectroscopy (Elsevier, Amsterdam, 2005), p 59-106. https://www. sciencedirect.com/science/article/pii/ B9780444516626500058?via\%3Dihub

33. R. Yang, Q. Jie, L. Min, and L. Guoqiang, Synthesis of Yttrium Aluminum Garnet (YAG) Powder by Homogeneous Precipitation Combined with Supercritical Carbon Dioxide or Ethanol Fluid Drying, J. Eur. Ceram. Soc., 2008, 28(15), p 2903-2914

34. N.P. Padture and P.G. Klemens, Low Thermal Conductivity in Garnets, J. Am. Ceram. Soc., 1997, 80(4), p 1018-1020

35. S.D. Parukuttyamma, J. Margolis, H. Liu, C.P. Grey, S. Sampath, H. Herman, and J.B. Parise, Yttrium Aluminum Garnet (YAG) Films Through a Precursor Plasma Spraying Technique, J. Am. Ceram. Soc., 2001, 84(8), p 1906-1908

36. R. Kumar, J. Wang, J. Chen, D. Cietek, J. Favata, S. Shahbazmohamadi, J. Roth, M. Gell, and E.H. Jordan, Low Thermal Conductivity Yttrium Aluminum Garnet Thermal Barrier Coatings Made by the Solution Precursor Plasma Spray: Part I Processing and Properties, J. Therm. Spray Technol., 2018, 27(5), p 781-793

37. R. Kumar, E. Jordan, M. Gell, J. Roth, C. Jiang, J. Wang, and S. Rommel, CMAS Behavior of Yttrium Aluminum Garnet (YAG) and Yttria-Stabilized Zirconia (YSZ) Thermal Barrier Coatings, Surf. Coat. Technol., 2017, 327, p 126-138

38. C.M. Weyant and K.T. Faber, Processing Microstructure Relationships for Plasma-Sprayed Yttrium Aluminum Garnet, Surf. Coat. Technol., 2008, 202(24), p 6081-6089

39. K.W. Schlichting, N.P. Padture, and P.G. Klemens, Thermal Conductivity of Dense and Porous Yttria-Stabilized Zirconia, $J$. Mater. Sci., 2001, 36(12), p 3003-3010

40. M. Ghatee, M.H. Shariat, and J.T.S. Irvine, Investigation of Electrical and Mechanical Properties of 3YSZ/8YSZ Composite Electrolytes, Solid State Ion., 2009, 180(1), p 57-62

41. www.advancedmaterials.us. $8 \mathrm{~mol} \%$ Yttria Stabilized Zirconia (YSZ) Powder, Superfine Grade. Website, 2018.

42. A. Ikesue, I. Furusato, and K. Kamata, Fabrication of Polycrystal Line, Transparent YAG Ceramics by a Solid-State Reaction Method, J. Am. Ceram. Soc., 1995, 78(1), p 225-228

43. H. Hayashi, T. Saitou, N. Maruyama, H. Inaba, K. Kawamura, and M. Mori, Thermal Expansion Coefficient of Yttria Stabilized Zirconia for Various Yttria Contents, Solid State Ion., 2005, 176(5-6), p 613-619

44. www.crystran.co.uk. Yttrium Aluminium Garnet (YAG). Website, 2018.

45. L.M. Candido, L.M.G. Fais, J.M.S.N. Reis, and L.A.P. Pinelli, Surface Roughness and Hardness of Yttria Stabilized Zirconia (yTZP) After 10 years of Simulated Brushing, Rev. Odontol. UNESP, 2014, 43(6), p 379-383

46. C.P. Khattak and F.F.Y. Wang, Perovskites and Garnets. Technical report, Brookhaven National Lab., Upton, 1976.

47. D.B. Sirdeshmukh, L. Sirdeshmukh, K.G. Subhadra, K. Kishan Rao, and S. Bal Laxman, Systematic Hardness Measurements on Some Rare Earth Garnet Crystal, Bull. Mater. Sci., 2001, 24(5), p $469-473$

48. G. Lijian, S. Zhao, X. Jiaying, Yu Hui, X. Fan, B. Zou, Y. Wang, and X. Cao, Phase Stability of Plasma Sprayed YAG-YSZ Composite Beads/Coatings at High Temperature, J. Eur. Ceram. Soc., 2013, 33(15-16), p 3325-3333

49. Y. Zhang and Yu Hongming, Synthesis of YAG Powders by the Co-Precipitation Method, Ceram. Int., 2009, 35(5), p 2077-2081

50. J. Li, X. Sun, S. Liu, X. Li, J.-G. Li, and D. Huo, A Homogeneous Co-Precipitation Method to Synthesize Highly Sinterability YAG Powders for Transparent Ceramics, Ceram. Int., 2015, 41(2), p 3283-3287 
51. F. Mubarok and N. Espallargas, Suspension Plasma Spraying of Sub-Micron Silicon Carbide Composite Coatings, J. Therm. Spray Technol., 2015, 24(5), p 817-825

52. B.R. Johnson and W.M. Kriven, Crystallization Kinetics of Yttrium Aluminum Garnet $\left(\mathrm{Y}_{3} \mathrm{Al}_{5} \mathrm{O}_{12}\right)$, J. Mater. Res., 2001, 16(06), p 1795-1805

53. H.N. Girish, C. Zhu, F.F. Ma, and G.Q. Shao. Synthesis of Cubic Yttrium Aluminum Garnet (YAG) Powders by Co-Precipitation and Two-Step Calcinations. In Conference: Advances in Energy Science and Environment Engineering: Proceedings of the 2017 International Workshop on Advances in Energy Science and Environment Engineering (AESEE 2017, 2017.

54. ISO 13320:2009—Particle Size Analysis-Laser Diffraction Methods. Standard Norge (www.standard.no), 2009.

55. M.R. Dorfman, Thermal Spray Coatings. In Handbook of Environmental Degradation of Materials, chapter 19.6-General Applications, 2nd edn (Elsevier, Amsterdam, 2012), p 587-593.

56. www.struers.com. About Grinding and Polishing-Mechanical Preparation-Troubleshooting. Website, 2018.
57. ASTM C1327-15: Standard Test Method for Vickers Indentation Hardness of Advanced Ceramics. ASTM International (ASTM.org), 2015.

58. S. Kochawattana, Phase Formation and Sintering of YAG Ceramics. Dissertation, The Pennsylvania State University, 2007.

59. Q. Liu, J. Liu, J. Li, M. Ivanov, A. Medvedev, Y. Zeng, G. Jin, X. Ba, W. Liu, B. Jiang, Y. Pan, and J. Guo, Solid-State Reactive Sintering of YAG Transparent Ceramics for optical applications, J. Alloys Compd., 2014, 616, p 81-88

60. P. Niranatlumpong, H. Koiprasert, C. Sukhonket, K. Ninon, and N. Coompreedee, TBC for Protection of Al Alloy Aerospace Component (World Academy of Science, Engineering and Technology, 2013).

Publisher's Note Springer Nature remains neutral with regard to jurisdictional claims in published maps and institutional affiliations. 